\title{
The effect of donor human milk on the length of hospital stay in very low birthweight infants: a systematic review and meta-analysis
}

\author{
Rui Yang ${ }^{1,2}$, Danqi Chen ${ }^{1,2}$, Qingqi Deng ${ }^{1,2}$ and Xinfen $X_{u^{2,3^{*}}}$ (i)
}

\begin{abstract}
Background: Donor human milk (DHM) is an alternative to preterm infant formula if the mother's own milk is not available. Since the lactation period and preservation treatment of DHM are different from those of mother's own milk, we aimed to determine the reduction in the length of hospital stay by DHM compared to preterm infant formula.

Methods: In this systematic review, we searched PubMed/MEDLINE, EMBASE, and the Cochrane Library to retrieve studies on the impact of DHM on the clinical outcomes of preterm infants published before 1 November 2019. The study included very low birthweight (VLBW) infants taking either DHM or infant formula with data on the length of hospital stay. Data were analysed using Review Manager 5.3 software.

Results: The literature search yielded 136 articles, and four randomised controlled trials (RCTs) and eight observational studies met the inclusion criteria. A meta-analysis of the RCTs $(N=725)$ showed no reduction in the length of hospital stay in both the DHM and infant formula groups ( -0.22 days; $95 \% \mathrm{Cl}-6.38,5.95$ days), whereas that of the eight observational studies $(N=2496)$ showed a significant reduction in the length of hospital stay in the DHM group (11.72 days; $95 \% \mathrm{Cl}-22.07,-1.37$ days). A subgroup analysis of the $\mathrm{RCT}$ s revealed that the incidence of necrotising enterocolitis (NEC) was significantly lower in the DHM group when the analysis included high-quality $R C T s(R R=0.32$; $95 \% \mathrm{Cl} 0.15,0.69)$.

Conclusions: This systematic review of RCTs showed that DHM neither prolonged nor shortened the length of hospital stay in VLBW infants compared to preterm infant formula; however, it reduced the incidence of NEC, further validating the protective role of DHM in the health and safety of VLBW infants.
\end{abstract}

Keywords: Donor human milk, Length of hospital stay, Preterm infant

\footnotetext{
* Correspondence: xuxinf@zju.edu.cn

Women's Hospital, School of Medicine, Zhejiang University, Hangzhou Zhejiang, China

${ }^{3}$ Haining Maternal and Child Health Hospital, Branch of Women's Hospital,

School of Medicine, Zhejiang University, Hangzhou, China

Full list of author information is available at the end of the article
}

C C The Author(s). 2020 Open Access This article is licensed under a Creative Commons Attribution 4.0 International License, which permits use, sharing, adaptation, distribution and reproduction in any medium or format, as long as you give appropriate credit to the original author(s) and the source, provide a link to the Creative Commons licence, and indicate if changes were made. The images or other third party material in this article are included in the article's Creative Commons licence, unless indicated otherwise in a credit line to the material. If material is not included in the article's Creative Commons licence and your intended use is not permitted by statutory regulation or exceeds the permitted use, you will need to obtain permission directly from the copyright holder. To view a copy of this licence, visit http://creativecommons.org/licenses/by/4.0/. The Creative Commons Public Domain Dedication waiver (http://creativecommons.org/publicdomain/zero/1.0/) applies to the data made available in this article, unless otherwise stated in a credit line to the data. 


\section{Background}

In the past few decades, advances in medical technology and treatment have greatly improved the survival rate of very low birthweight (VLBW) infants; however, they have not reduced the corresponding morbidity [1-3]. Many complications threaten the quality of life of VLBW infants [4]. Neonatal intensive care is associated with high healthcare costs in the economy and society.

Human milk is increasingly recognised for its nutritional and immune effects on neonates, including preterm infants [5]. The American Academy of Pediatrics recommends donor human milk (DHM) as an alternative feeding method if the mother's own milk is not available [6]. The World Health Organization (WHO), UNICEF, American Academy of Pediatrics, and Japan Pediatric Society suggest that DHM has many advantages compared to preterm infant formula when feeding VLBW infants [7-9]. The European Society for Paediatric Gastroenterology, Hepatology, and Nutrition recommends that preterm infant formula should be used only when DHM and mother's own milk are not available [10]. There is ample supporting evidence that mother's own milk diet in preterm infants can reduce the incidence of late-onset sepsis, bronchopulmonary dysplasia (BPD), retinopathy of prematurity (ROP), and necrotising enterocolitis (NEC), as well as improve feeding tolerance, shorten the length of hospital stay, and reduce medical costs [11-13]. DHM and mother's own milk are not completely equivalent because DHM may be obtained in a different lactation stage and is pasteurised; whether DHM is as good as mother's own milk when compared to infant formula still needs to be studied. Long hospital stay predisposes VLBW infants to hospital environment-related risks, such as nosocomial infections, noise, and lighting, that may affect development $[14,15]$. Studies have shown a positive correlation between shorter hospital stays and better clinical outcomes, lower mortality rates, and fewer readmissions $[16,17]$. Similarly, a longer hospital stay can affect the establishment of mother-to-infant or parents-infant attachment [18]. Similarly, the increased hospital stay would affect the allocation of health resources, reducing the number of available Neonatal Intensive Care Unit (NICU) beds and restricting other preterm infants who require hospital care from admission to the NICU. For families with preterm infants, a long hospital stay can cost more, increase visits to hospitals, and cause negative emotions [18-22]. It is not uncommon for a NICU admission to cost more than $\$ 3500$ per day for a baby, and long-term hospitalisation costs can exceed \$1 million [23]. We aimed to conduct a systematic review of randomised controlled trials (RCTs) and observational studies to analyse the impact of DHM on the length of hospital stay in VLBW infants using a meta-analytic approach. The length of hospital stay was regarded as the primary outcome, whereas NEC was the secondary research outcome.

\section{Methods}

We developed a protocol detailing the review question, search strategy, inclusion criteria, data extraction, study quality assessment, and strategy for data synthesis. This protocol has been registered on the International Prospective Register of Systematic Reviews (PROSPERO) with the ID of CRD42019133797 and is available from https://www.crd.york.ac.uk/prospero/display_rec ord.php? ID = CRD42019133797. This article is a systematic review, and the Women's Hospital School of Medicine Zhejiang University Medical Ethics Committee reviewed it for exemption.

\section{Search strategies}

A literature retrieval was conducted among studies published before 1 November 2019 in PubMed / MEDL INE, EMBASE, and the Cochrane Library. The PubMed search strategy used the following terms, including $\mathrm{MeSH}$ terms: (donor milk [Title/Abstract], donor breast milk [Title/Abstract], banked milk [Title/Abstract], "pasteurized human milk" [Title/Abstract], or donor human milk [Title/Abstract]) plus (Infant, Very Low Birth Weight $[\mathrm{MeSH}])$. Using this strategy, the length of hospital stay mostly appeared in the study results rather than the title or abstract; hence, it was not used as one of the search terms. Similar search strategies were used in other databases. No language restrictions were placed on the search results, and translations were made if necessary. RCTs and observational studies evaluating DHM feeding versus formula in VLBW infants were included. Systematic reviews, literature reviews, case studies, qualitative studies, and commentaries were not included but were examined to help identify additional applicable studies.

\section{Inclusion criteria}

Studies meeting the following inclusion criteria were included in the study: 1) study designs involving RCTs and quasi-experimental and observational studies, 2) study population, including very low birthweight infants, with weights $<1500 \mathrm{~g}$ or gestational age $<32$ weeks, 3) studies grouping subjects according to the feeding protocol, including a DHM group and a infant formula group; we defined the DHM and formula groups as either DHM or formula, respectively, accounting for more than $75 \%$ of the total enteral diet, and 4) studies wherein reported outcomes included the length of hospital stay. If several studies targeted the same patients, the study could be included if it met the above inclusion criteria and was published earlier.

\section{Data extraction}

The researchers conducted a preliminary screening of the titles and abstracts of the studies retrieved through the search strategy. Two researchers (RY, DQC) further reviewed the studies and extracted the following 
information and data: study design, study population, inclusion criteria, primary outcome(s), intervention/groups, length of hospital stay, and incidence of complications. The results of the two researchers' (RY and DQC) assessments of RCTs were consistent. The interrater-reliability of the observational studies was calculated using SPSS $26.0(\mathrm{k}=0.826)$, showing a good agreement between the two researchers. The mean and standard deviation (SD) of continuous variables and the percentage of dichotomous variables in the outcome measure were extracted. We contacted the authors of studies with insufficient data for more detailed information and data. One article [24] was excluded because there was no reply.

\section{Quality assessment}

Risk of bias in RCTs was assessed using the Cochrane Collaboration and the Working Group for Grading of Recommendations Assessment, Development, and Evaluation
(GRADE) [25]. RCTs were assessed for the risk of bias through The Cochrane Collaboration's tool for assessing the risk of bias. Each item was assessed according to the manual, and risks were accordingly categorised as high, moderate, or low. The risk of bias in observational studies was assessed using the Newcastle-Ottawa Scale (NOS) [26] for quality assessment. A star was given if the study matched the description of an item in the NOS manual; studies could receive 1-9 stars (three domains with eight items in total; one item in the comparability section is divided into two). Two investigators independently evaluated the included studies, and studies for which consensus was not reached on quality assessment were evaluated by a third investigator.

\section{Statistical analysis}

Data analysis was performed with the Review Manager 5.3 software. Relative risk (RR) was calculated with a

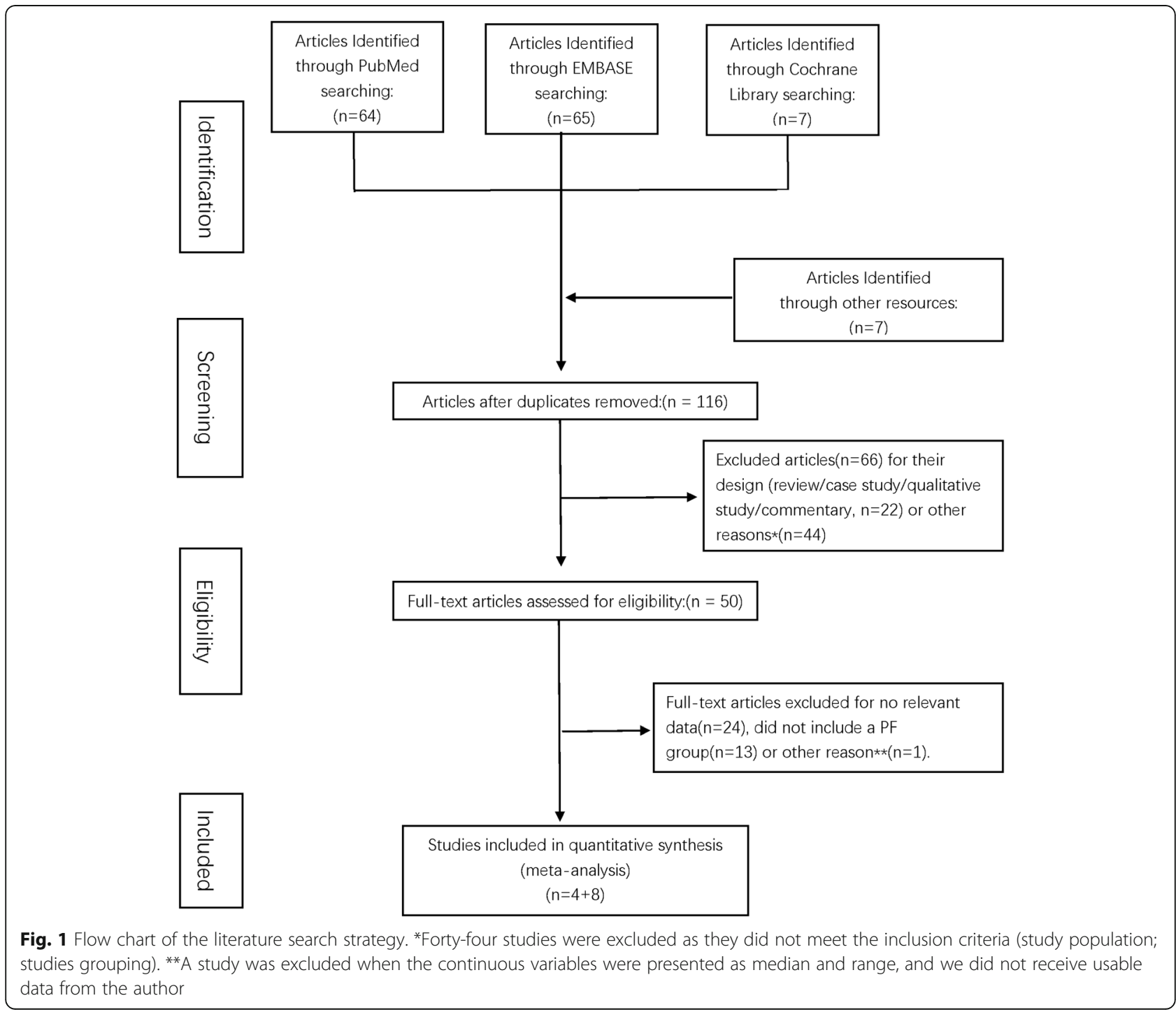




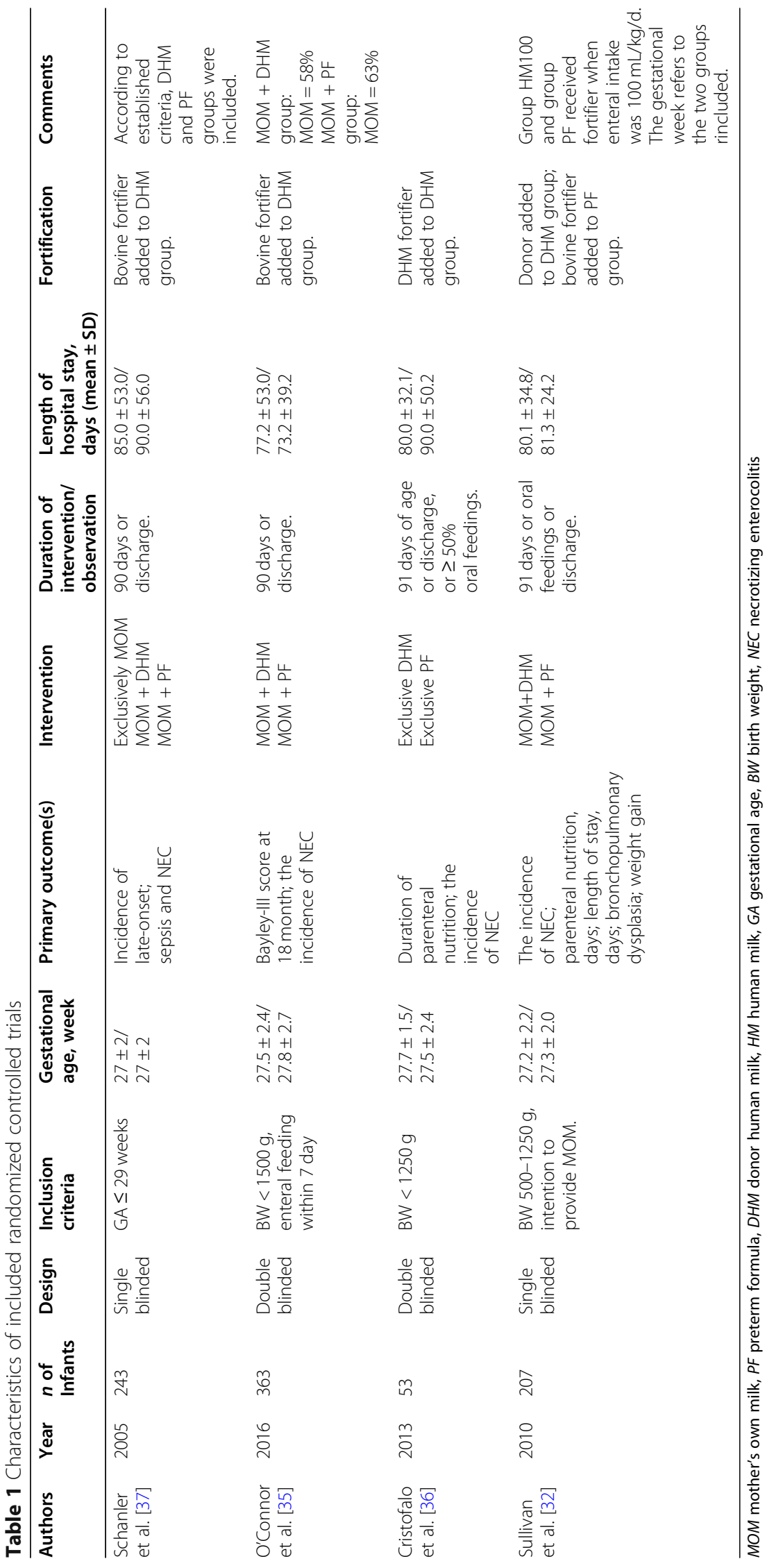




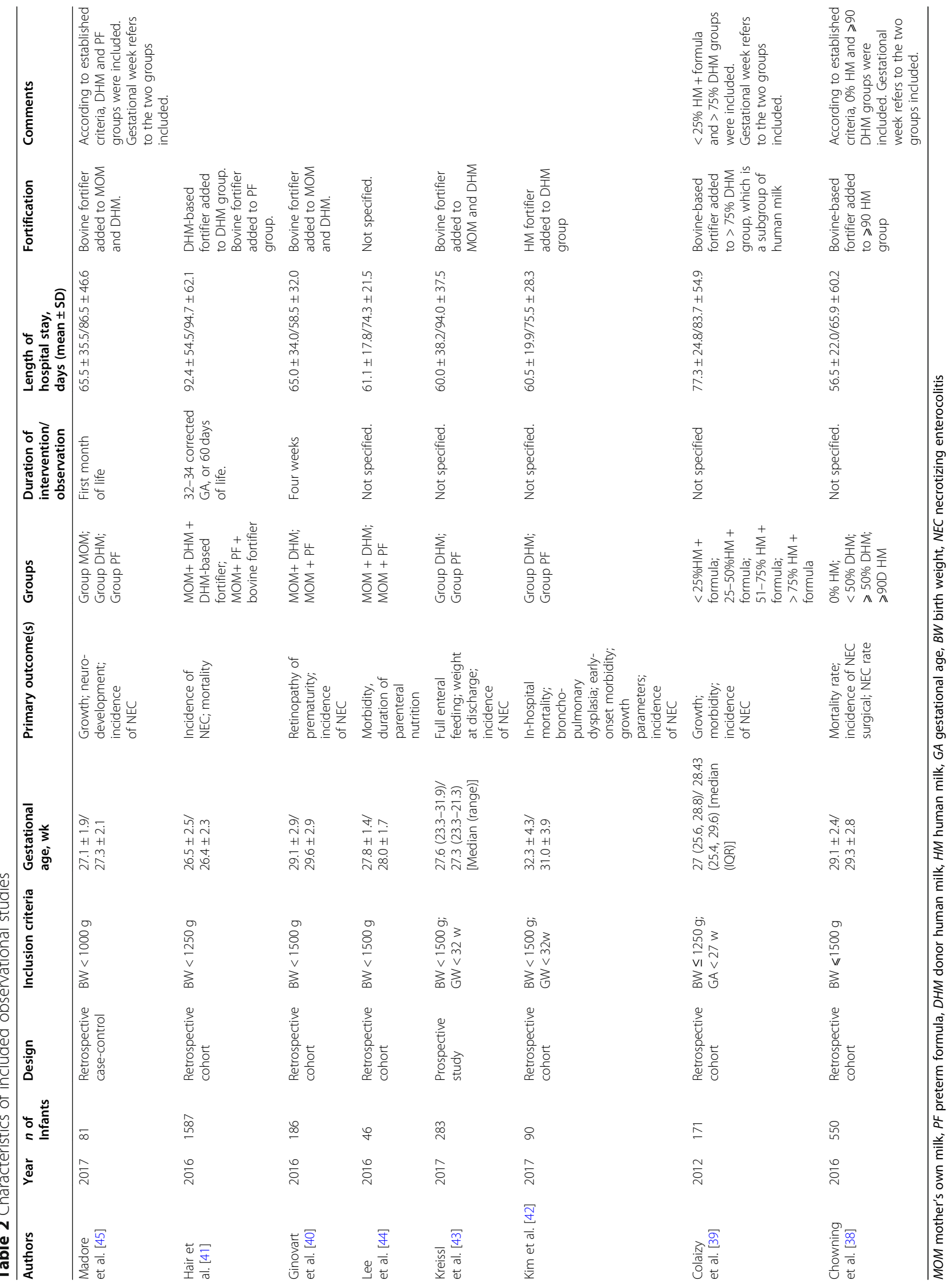


95\% confidence interval (CI) for the dichotomous variable (incidence of NEC). The mean difference (MD) was calculated with 95\% CI for continuous variables. To retain valuable studies' information, studies that provided only the median and interquartile range were included in the analysis. After consulting other metaanalyses that included studies only reporting the median and interquartile range, Wan et al.'s [27] method was applied here to estimate the mean and SD. A study presenting continuous variables as median and range was excluded, and we did not receive usable data from the author. The random-effect model was used to describe the combined effect size. Sensitivity analysis was performed when investigating the effect of individual studies on the combined effect size.

\section{Results}

The literature search per the search strategy yielded 136 articles on completion, and seven potential articles [5, 28-33] were identified by reading reviews or from other resources. Fifty full-text articles were assessed for eligibility after reading the titles and abstracts of 116 articles and removing duplicates. Twenty-four articles were excluded for missing data, such as length of NICU stay, 13 reports were excluded due to the absence of an infant formula group, and a retrospective study [34] was excluded because its data was obtained from one of the RCTs [35] already included. In total, 12 studies, including 4 RCTs [32, 35-37] and 8 observational studies [38-45], that focused on DHM feeding and hospitalisation outcomes in VLBW infants were identified (Fig. 1).

The details of the included studies are shown in Table 1 (RCTs) and Table 2 (observational studies). The four RCTs included 358 VBLW infants fed with DHM and 367 VBLW infants fed with infant formula. Two studies $[35,37]$ were assessed as having a low risk of bias in all aspects and the other two studies as having high risk due to blinding of participants and/or personnel blinding to outcome assessment following the Cochrane Collaboration's tool. The eight observational studies reported 1306 VBLW infants fed with DHM and 1190 VBLW infants fed with infant formula. Four of the eight studies were rated 9-star in the assessment of the risk of bias, three studies were rated 7-star for not meeting criteria in the comparability section, and one study was rated 6-star. The details of the study assessments are reported in Table 3 (RCTs) and Table 4 (observational studies).

The publication bias of the RCTs included was invisibility on a funnel plot due to the limited number of studies. No evidence of publication bias was found in the analysis. The observational studies did not reveal publication bias through the use of the Egger's test $(p=0.097)$.

\section{Effects on length of hospital stay}

The length of hospital stay of 725 infants from four RCT studies was measured. The meta-analysis did not demonstrate a significant reduction in length of hospital stay in the DHM group compared to the infant formula group ( -0.22 days; $95 \%$ CI $-6.38,5.95$ days; $p=0.94)$. The heterogeneity was not significant $\left(\mathrm{I}^{2}=0 \%, p=0.62\right)$. Eight observational studies with 2496 infants were included in the meta-analysis, and a significant reduction in length of hospital stay for infants receiving DHM (- 11.72 days; 95\% CI -22.07,1.37 days; $p=0.03$ ) was observed. The heterogeneity was statistically significant $\left(\mathrm{I}^{2}=86 \%, p=0.03\right)$. The forest plot of the effect is presented in Fig. 2.

\section{Effects on NEC}

Four RCT studies with a total sample of 725 infants measured the occurrence rates of infant NEC. The meta-analysis did not find a significantly lower risk ratio for NEC in the DHM group compared with the control group $(\mathrm{RR}=0.55 ; 95 \% \mathrm{CI} 0.26,1.18 ; p=0.13)$. The heterogeneity was statistically significant $\left(\mathrm{I}^{2}=62 \%, p=\right.$ 0.05). Eight observational studies with 2496 infants were included in the meta-analysis, and a significant reduction in the occurrence of NEC was observed in infants receiving DHM (RR $=0.48$; 95\% CI 0.35, 0.66; $p<0.05)$. The heterogeneity was not statistically significant $\left(\mathrm{I}^{2}=7 \%, p=0.37\right)$, and the forest plot of the effect is presented in Fig. 3.

A subgroup analysis (Fig. 3c) of RCTs indicated that the effect of DHM on NEC was statistically significant in reducing the incidence of NEC when the subgroup analysis was restricted to high-quality $R C T s$ ( $R R=0.32$; $95 \%$

Table 3 Assessment of risk of bias of included randomized controlled trials ${ }^{a}$

\begin{tabular}{lllllllll}
\hline & $\begin{array}{l}\text { Random } \\
\text { sequence } \\
\text { generation }\end{array}$ & $\begin{array}{l}\text { Allocation } \\
\text { concealment }\end{array}$ & $\begin{array}{l}\text { Blinding of } \\
\text { participants } \\
\text { and personnel }\end{array}$ & $\begin{array}{l}\text { Blinding of } \\
\text { outcome } \\
\text { assessment }\end{array}$ & $\begin{array}{l}\text { Incomplete } \\
\text { outcome data }\end{array}$ & $\begin{array}{l}\text { Selective } \\
\text { reporting }\end{array}$ & $\begin{array}{c}\text { Other bias } \\
\text { Total }\end{array}$ \\
\hline O'Connor et al. [35] $^{\prime}$ & A & A & A & A & A & A & A & A \\
Sullivan et al. [32] & A & A & C & A & A & A & A & C \\
Schanler et al. [37] & A & A & C & C & A & A & A & C \\
Cristofalo et al. [36] & A & A & A & A & A & A & A & A \\
\hline
\end{tabular}

${ }^{a} \mathrm{~A}$, high risk; $\mathrm{B}$, moderate risk; $\mathrm{C}$, low risk 
Table 4 Assessment of the quality of included observational studies $^{a}$

\begin{tabular}{lllll}
\hline & Selection & Comparability & Outcome & Total \\
\hline Lee et al. [44] & 4 & 0 & 2 & 6 \\
Kreissl et al. [43] & 4 & 0 & 3 & 7 \\
Kim et al. [42] & 4 & 2 & 3 & 9 \\
Colaizy et al. [39] & 4 & 2 & 3 & 9 \\
Chowning et al. [38] & 4 & 2 & 3 & 9 \\
Hair et al. [41] & 4 & 0 & 3 & 7 \\
Madore et al. [45] & 4 & 2 & 3 & 9 \\
Ginovart et al. [40] & 4 & 0 & 3 & 7 \\
\hline a Numbers repesent
\end{tabular}

a Numbers represent the total number of stars obtained by the observational study in each quality domain

CI $0.15,0.69 ; p=0.004)$, and the heterogeneity was not significant $\left(\mathrm{I}^{2}=0 \%, p=0.51\right)$.

\section{Discussion}

From the meta-analysis of the pooled RCTs data, DHM was not observed to affect the length of hospital stay of VLBW infants. There was no evidence that DHM lowered the incidence of NEC in VLBW infants; however, a meta-analysis of high-quality RCTs did reveal that DHM significantly reduced the incidence of NEC, whereas that of observational studies (eight studies) showed an improvement in length of hospital stay in the DHM group when compared to the infant formula group. Additionally, a meta-analysis of observational studies (eight studies) also revealed that feeding infants with DHM compared to infant formula reduced the incidence of major medical complications, such as NEC.

Length of hospital stay is a complex measure that has many interfering factors. Multiple factors, other than nutritional intake, have been identified as confounding variables associated with infant development and may even manifest before birth [46]. For VLBW infants, the difference in birth weight of $100 \mathrm{~g}$ or 1 week of gestational age can have a significant impact on perinatal and postnatal complications. These complications have a direct or indirect effect on the length of hospital stay in these infants and are likely to confound the influences of DHM [47].

DHM may influence the length of hospital stay as follows: (a) by improving the nutrition and growth of infants; (b) by reducing the incidence of late-onset sepsis in VLBW [48, 49]; and (c) through critical nutrients, such as long-chain polyunsaturated fatty acids (LCPUFA), and possibly other neurotrophic factors of human milk.

One randomised, blinded trial on the feeding of extremely preterm infants included in this analysis concluded that DHM offered a minute short-term advantage over infant formula and mother's own milk and was associated with fewer infection-related events and shorter hospital stay [37]. The study by O'Connor et al. [35] was a pragmatic, double-blind, randomised trial conducted in four tertiary care NICUs. Similarly, this study found no advantage of feeding VLBW infants with DHM compared to formula at a corrected age of 18 months, as assessed by the Bayley-III. DHM and mother's own milk

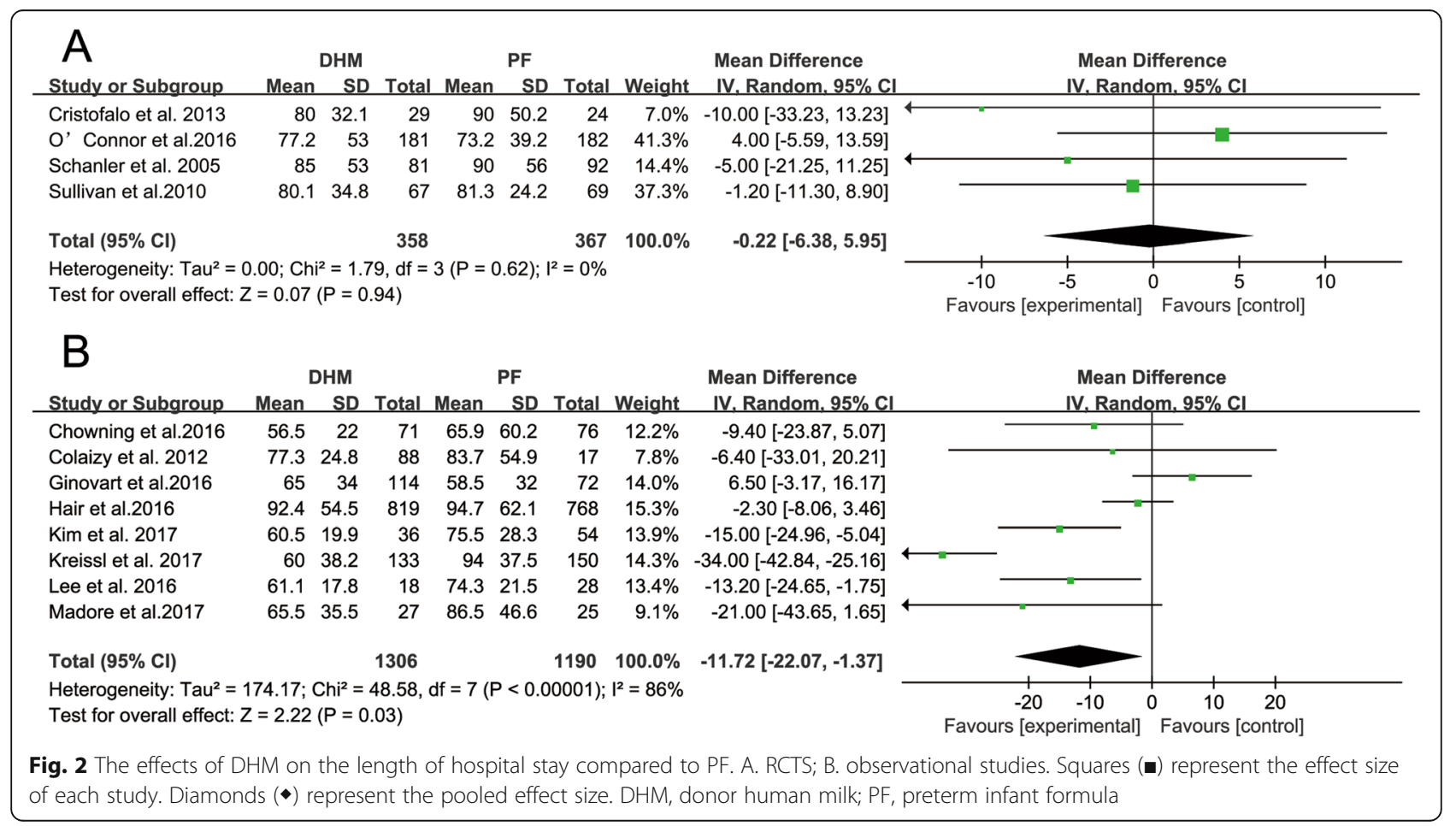




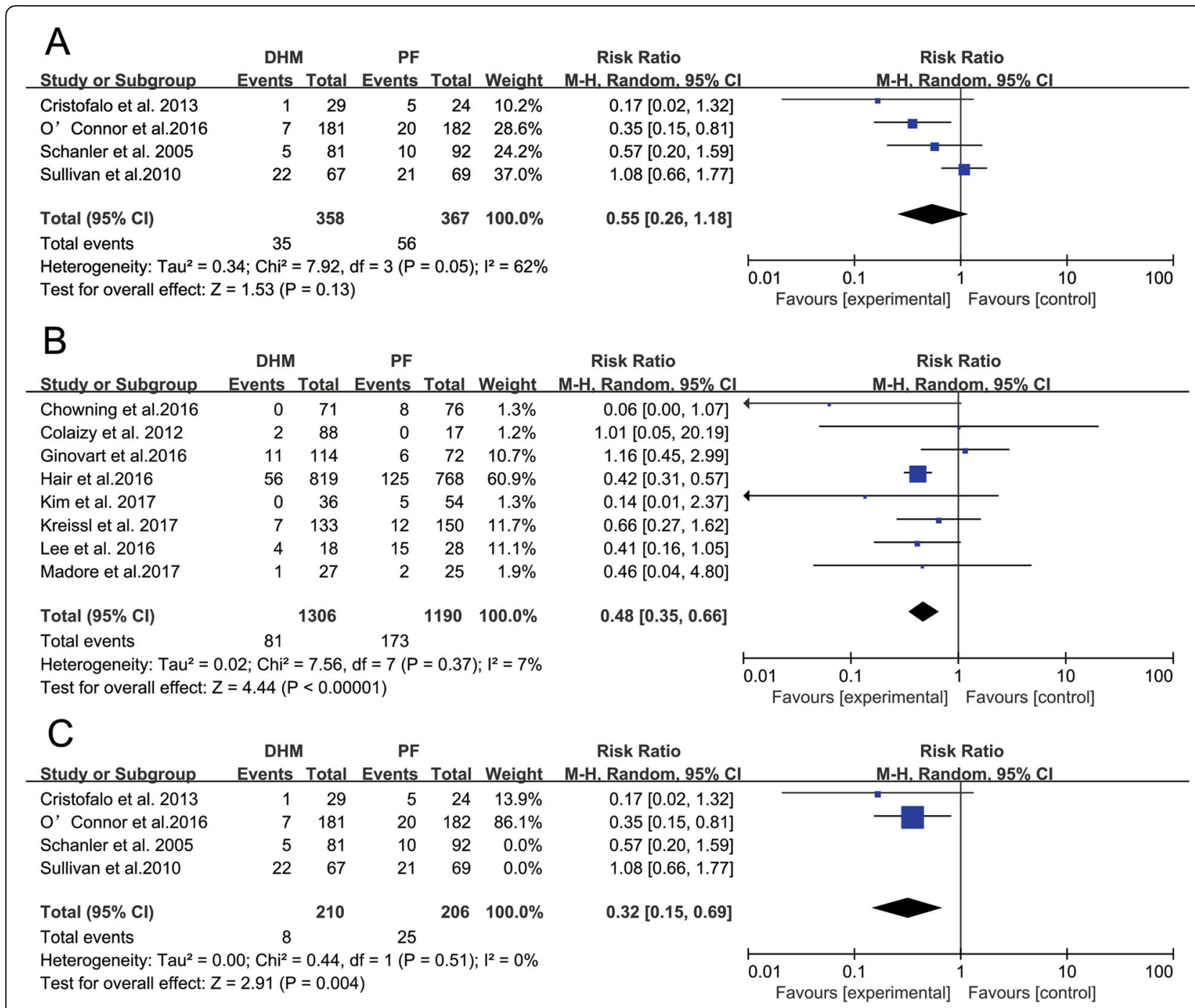

Fig. 3 The effects of DHM on NEC compared to PF. A. RCTS; B. observational studies; C. high-quality RCTs studies. Squares ( $\mathbf{m})$ represent the effect size of each study. Diamonds $(\bullet)$ represent the pooled effect size. DHM, donor human milk; PF, preterm infant formula

differ in their bioactive components, such as live cells and lactoferrin, that play an important role in reducing morbidity (e.g. sepsis). This is due to the process of pasteurisation, which in turn affects neurodevelopment, and might be the reason why the hypothesised improvement associated with DHM was not observed.

Studies have shown that DHM may differ depending on the specific circumstances of the donor mother and the process of pasteurisation [50-52]. The composition of breast milk is related to the mother's dietary habits, environment, and lactation period. Pasteurisation eliminates immune cells in human milk but does not completely obliterate biological activity, with many bioactive components preserved, including cytokines and growth factors [53]. The timing, volume, and duration of human milk may have an impact on the development of infants. The advantages of human milk in the neurodevelopment of infants are not only reflected during hospitalisation, but after discharge as well [54]. Breastfeeding is an unmatched way of providing ideal food for the healthy growth and development of infants. WHO actively promotes human milk as the best source of nourishment for infants [8]. More research is needed to investigate whether DHM is a priority choice for infants when the mother's own milk is unavailable.

The included RCTs did not find beneficial shortterm outcomes in feeding DHM as a substitution to extremely preterm infants; however, long-term outcomes of infants fed with DHM compared to infant formula need to be investigated. As the use of DHM increases, due to the differences between DHM and mother's own milk, the DHM processing and DHM protocol in the NICU will require high-quality clinical assessments. 
The present study has the following limitations: 1) the number of included RCTs is small; 2) none of the RCTs were initially designed to investigate the effect of DHM on the length of hospital stay in preterm infants; 3) the included RCTs were conducted over a specific period, which may introduce bias; and 4) fortification strategies among DHM studies were different, especially regarding the type of fortification (bovine vs. human milk). Despite these limitations, this systematic review revealed that there are benefits in feeding VLBW infants with DHM compared to infant formula.

\section{Conclusions}

This systematic review of RCTs showed that DHM neither prolonged nor shortened the length of hospital stay in VLBW infants compared to infant formula; however, it reduced the incidence of NEC. Our results are consistent with previously published reviews focusing on the effects of DHM on NEC [11, 55, 56]. Although observational studies have certain methodological limitations, the data suggest that DHM can shorten the length of hospital stay and reduce the incidence of NEC in VLBW infants, further proving the protective effect of DHM on the health and safety of VLBW. Therefore, health facilities should consider improving the application of DHM for VLBW. Similarly, human milk banks should increase publicity on human milk donations and establish increased DHM's reserves to prepare for its widespread application.

\section{Abbreviations \\ BPD: Bronchopulmonary dysplasia; DHM: Donor human milk; GRADE: Grading of recommendations assessment, development, and evaluation; LCPUFA: Long-chain polyunsaturated fatty acids; MD: Mean difference; NEC: Necrotising enterocolitis; NICU: Neonatal Intensive Care Unit; NOS: Newcastle-Ottawa Scale; RCTs: Randomised controlled trials; ROP: Retinopathy of prematurity; SD: Standard deviation; VLBW: Very low birth weight; WHO: World Health Organization}

\section{Acknowledgements}

We appreciate Editage for assistance in editing this manuscript.

\section{Authors' contributions}

The authors' responsibilities were as follows - RY: conceptualized and designed the study, collected the data, conducted the statistical analysis, drafted, edited, submitted the manuscript, and critically revised the article; DQC and QQD: critically reviewed and revised the manuscript, and interpreted the data; and all authors: interpreted the data, revised the manuscript, approved the final manuscript and agreed to be accountable for all aspects of the work.

\section{Funding}

Not applicable.

\section{Availability of data and materials}

Not applicable.

\section{Ethics approval and consent to participate}

This article is a meta-analysis. The Women's Hospital School of Medicine Zhejiang University Medical Ethics Committee reviewed and exempted the study. The requirement for informed consent was waived due to the nature of the study.
Consent for publication

Not applicable.

\section{Competing interests}

The authors declare that they have no competing interest.

\section{Author details}

${ }^{1}$ Nursing Faculty, School of Medicine, Zhejiang University, Hangzhou, China. 'Women's Hospital, School of Medicine, Zhejiang University, Hangzhou, Zhejiang, China. ${ }^{3}$ Haining Maternal and Child Health Hospital, Branch of Women's Hospital, School of Medicine, Zhejiang University, Hangzhou, China.

Received: 31 March 2020 Accepted: 16 October 2020

Published online: 28 October 2020

References

1. Su YY, Wang SH, Chou HC, Chen CY, Hsieh WS, Tsao PN, et al. Morbidity and mortality of very low birth weight infants in Taiwan-changes in 15 years: a population based study. J Formos Med Assoc. 2016;115(12):1039-45.

2. Varga P, Berecz B, Gasparics A, Dombi Z, Varga Z, Jeager J, et al. Morbidity and mortality trends in very-very low birth weight premature infants in light of recent changes in obstetric care. Eur J Obstet Gynecol Reprod Biol. 2017; 211:134-9.

3. Ballot DE, Chirwa T, Ramdin T, Chirwa L, Mare I, Davies VA, et al. Comparison of morbidity and mortality of very low birth weight infants in a central Hospital in Johannesburg between 2006/2007 and 2013. BMC Pediatr. 2015;15:20.

4. Guinsburg R, de Almeida MF, de Castro JS, Silveira RC, Caldas JP, Fiori HH, et al. Death or survival with major morbidity in VLBW infants born at Brazilian neonatal research network centers. J Matern Fetal Neonatal Med. 2016:29(6):1005-9.

5. Lee HC, Kurtin PS, Wight NE, Chance K, Cucinotta-Fobes T, Hanson-Timpson TA, et al. A quality improvement project to increase breast milk use in very low birth weight infants. Pediatrics. 2012;130(6):1679-87.

6. Cacho NT, Harrison NA, Parker LA, Padgett KA, Lemas DJ, Marcial GE, et al. Personalization of the microbiota of donor human milk with mother's own milk. Front Microbiol. 2017;8:1470.

7. Brandstetter S, Mansen K, DeMarchis A, Nguyen Quyhn N, Engmann C, Israel-Ballard K. A decision tree for donor human milk: an example tool to protect, promote, and support breastfeeding. Front Pediatr. 2018;6:324.

8. World Health Organization. The World Health Organization's infant feeding recommendation. https://www.who.int/nutrition/topics/infantfeeding_ recommendation/en/. Accessed 1 May 2001.

9. Mizuno K, Shimizu T, Ida S, Ito S, Inokuchi M, Ohura T, et al. Policy statement of enteral nutrition for preterm and very low birthweight infants. Pediatr Int. 2020;62(2):124-7.

10. Lapillonne A, Bronsky J, Campoy C, Embleton N, Fewtrell M, Fidler Mis N, et al. Feeding the late and moderately preterm infant: a position paper of the european society for paediatric gastroenterology, hepatology and nutrition committee on nutrition. J Pediatr Gastroenterol Nutr. 2019;69(2): 259-70

11. Maffei D, Schanler RJ. Human milk is the feeding strategy to prevent necrotizing enterocolitis! Semin Perinatol. 2017;41(1):36-40.

12. Miller J, Tonkin E, Damarell R, McPhee A. A systematic review and metaanalysis of human milk feeding and morbidity in very low birth weight infants. Nutrients. 2018;10(6):707-42.

13. Dritsakou K, Liosis G, Valsami G, Polychronopoulos E, Souliotis K, Skouroliakou M. Mother's breast milk supplemented with donor milk reduces hospital and health service usage costs in low-birthweight infants. Nutrients. 2016:40:109-13.

14. Santos J, Pearce SE, Stroustrup A. Impact of hospital-based environmental exposures on neurodevelopmental outcomes of preterm infants. Curr Opin Pediatr. 2015;27(2):254-60.

15. Seaton SE, Barker L, Draper ES, Abrams KR, Modi N, Manktelow BN. Estimating neonatal length of stay for babies born very preterm. Arch Dis Child Fetal Neonatal Ed. 2019;104(2):182-6.

16. Osnabrugge RL, Speir AM, Head SJ, Jones PG, Ailawadi G, Fonner CE, et al. Cost, quality, and value in coronary artery bypass grafting. J Thorac Cardiovasc Surg. 2014;148(6):2729-35.

17. Stambough JB, Nunley RM, Curry MC, Steger-May K, Clohisy JC. Rapid recovery protocols for primary total hip arthroplasty can safely reduce 
length of stay without increasing readmissions. J Arthroplast. 2015;30(4): 521-6.

18. Merritt TA, Pillers D, Prows SL. Early NICU discharge of very low birth weight infants- a critical review and analysis. Semin Neonatol. 2003;8(2):95-115.

19. Baker A. Crossing the quality chasm: a new health system for the 21 st century. BMJ. 2001;323(7322):1192.

20. Turner M, Chur-Hansen A, Winefield H. Mothers' experiences of the NICU and a NICU support group programme. J Reprod Infant Psychol. 2015;33(2):165-79.

21. Holditch-Davis D, Santos H, Levy J, White-Traut R, O'Shea TM, Geraldo V, et al. Patterns of psychological distress in mothers of preterm infants. Infant Behav Dev. 2015;41:154-63.

22. Flacking $\mathrm{R}$, Lehtonen $\mathrm{L}$, Thomson $\mathrm{G}$, Axelin A, Ahlqvist $\mathrm{S}$, Moran $\mathrm{VH}$, et al. Closeness and separation in neonatal intensive care. Acta Paediatr. 2012; 101(10):1032-7.

23. Muraskas J, Parsi K. The cost of saving the tiniest lives: NICUs versus prevention. Virtual Mentor. 2008;10(10):655-8.

24. Verd S, Porta R, Botet F, Gutiérrez A, Ginovart G, Barbero AH, et al. Hospital outcomes of extremely low birth weight infants after introduction of donor milk to supplement mother's milk. Breastfeed Med. 2015;10(3):150-5.

25. Yuan Z, Akl E, Schünemann H. Using systematic reviews in guideline development: the GRADE approach. Res Synth Methods. 2019;10(3):312-29.

26. Lo CK, Mertz D, Loeb M. Newcastle-Ottawa scale: comparing reviewers' to authors' assessments. BMC Med Res Methodol. 2014;14:45.

27. Wan $X$, Wang W, Liu J, Tong T. Estimating the sample mean and standard deviation from the sample size, median, range and/or interquartile range. BMC Med Res Methodol. 2014;14:135.

28. Parker LA, Krueger C, Sullivan S, Kelechi T, Mueller M. Effect of breast milk on hospital costs and length of stay among very low-birth-weight infants in the NICU. Adv Neonatal Care. 2012;12(4):254-9.

29. Assad M, Elliott MJ, Abraham JH. Decreased cost and improved feeding tolerance in VLBW infants fed an exclusive human milk diet. J Perinatol. 2016;36(3):216-20.

30. Lloyd ML, Malacova E, Hartmann B, Simmer K. A clinical audit of the growth of preterm infants fed predominantly pasteurised donor human milk $v$. those fed mother's own milk in the neonatal intensive care unit. Br J Nutr. 2019;121(9):1-8.

31. Seok M, Ryu SW. Exclusive human breast milk versus bovine milk-based formula in the feeding of very low birth weight infants. Clin Nutr. 2016;35:43.

32. Sullivan S, Schanler RJ, Kim JH, Patel AL, Trawöger R, Kiechl-Kohlendorfer U, et al. An exclusively human milk-based diet is associated with a lower rate of necrotizing enterocolitis than a diet of human milk and bovine milkbased products. J Pediatr. 2010;156(4):562-7.

33. Tshamala D, Pelecanos A, Davies MW. Factors associated with infants receiving their mother's own breast milk on discharge from hospital in a unit where pasteurised donor human milk is available. J Paediatr Child Health. 2018;54(9):1016-22.

34. Trang S, Zupancic JAF, Unger S, Kiss A, Bando N, Wong S, et al. Costeffectiveness of supplemental donor milk versus formula for very low birth weight infants. Pediatrics. 2018:141(3):e20170737.

35. O'Connor DL, Gibbins S, Kiss A, Bando N, Brennan-Donnan J, Ng E, et al. Effect of supplemental donor human milk compared with preterm formula on neurodevelopment of very low-birth-weight infants at 18 months: a randomized clinical trial. JAMA. 2016:316(18):1897-905.

36. Cristofalo EA, Schanler RJ, Blanco CL, Sullivan S, Trawoeger R, KiechlKohlendorfer $\mathrm{U}$, et al. Randomized trial of exclusive human milk versus preterm formula diets in extremely premature infants. J Pediatr. 2013;163(6):1592-5.

37. Schanler RJ, Lau C, Hurst NM, Smith EO. Randomized trial of donor human milk versus preterm formula as substitutes for mothers' own milk in the feeding of extremely premature infants. Pediatrics. 2005;116(2):400-6.

38. Chowning R, Radmacher P, Lewis S, Serke L, Pettit N, Adamkin DH. A retrospective analysis of the effect of human milk on prevention of necrotizing enterocolitis and postnatal growth. J Perinatol. 2016;36(3):221-4.

39. Colaizy TT, Carlson S, Saftlas AF, Morriss FH Jr. Growth in VLBW infants fed predominantly fortified maternal and donor human milk diets: a retrospective cohort study. BMC Pediatr. 2012;12:124.

40. Ginovart G, Gich I, Verd S. Human milk feeding protects very low-birthweight infants from retinopathy of prematurity: a pre-post cohort analysis. J Matern Fetal Neonatal Med. 2016;29(23):3790-5.

41. Hair AB, Peluso AM, Hawthorne KM, Perez J, Smith DP, Khan JY, et al. Beyond necrotizing enterocolitis prevention: improving outcomes with an exclusive human milk-based diet. Breastfeed Med. 2016;11(2):70-4.
42. Kim EJ, Lee NM, Chung SH. A retrospective study on the effects of exclusive donor human milk feeding in a short period after birth on morbidity and growth of preterm infants during hospitalization. Medicine (Baltimore). 2017; 96(35):e7970.

43. Kreissl A, Sauerzapf E, Repa A, Binder C, Thanhaeuser M, Jilma B, et al. Starting enteral nutrition with preterm single donor milk instead of formula affects time to full enteral feeding in very low birthweight infants. Acta Paediatr. 2017;106(9):1460-7.

44. Lee SH, Park JH, Kim CS, Lee SL. Clinical findings according to feeding diets in very low birth weight infants: human breast milk versus bovine milkbased formula. Neonatal Med. 2016;23(1):23-9.

45. Madore LS, Bora S, Erdei C, Jumani T, Dengos AR, Sen S. Effects of donor breastmilk feeding on growth and early neurodevelopmental outcomes in preterm infants: an observational study. Clin Ther. 2017;39(6):1210-20.

46. Koo. W, Tank. S, Martin. S, Shi. R. Human milk and neurodevelopment in children with very low birth weight: a systematic review. Nutr J. 2014;13:94.

47. NICHD Neonatal Research Network (NRN). Extremely Preterm Birth Outcome Data. https://www.nichd.nih.gov/about/org/der/branches/ppb/programs/ epbo-espanol/epbo_caseestimates. Accessed 2 Apr 2020.

48. Bender GJ, Koestler D, Ombao H, McCourt M, Alskinis B, Rubin LP, et al. Neonatal intensive care unit: predictive models for length of stay. J Perinatol. 2013;33(2):147-53.

49. Lee HC, Bennett MV, Schulman J, Gould JB. Accounting for variation in length of NICU stay for extremely low birth weight infants. J Perinatol. 2013; 33(11):872-6.

50. Martin CR, Ling PR, Blackburn GL. Review of infant feeding: key features of breast milk and infant formula. Nutrients. 2016;8:5.

51. Mosca F, Gianni ML. Human milk: composition and health benefits. Am J Clin Nutr. 2017;39(2):48-53.

52. Pines N, Mandel D, Mimouni FB, Moran Lev H, Mangel L, Lubetzky R. The effect of between-breast differences on human milk macronutrients content. J Perinatol. 2016;36(7):549-51.

53. O'Connor DL, Ewaschuk JB, Unger S. Human milk pasteurization: benefits and risks. Curr Opin Clin Nutr Metab Care. 2015;18(3):269-75.

54. Lucas A, Morley R, Cole T, Lister G, Leeson-Payne C. Breast milk and subsequent intelligence quotient in children born preterm. Lancet. 1992; 339(8788):261-4.

55. Buckle A, Taylor C. Cost and cost-effectiveness of donor human milk to prevent necrotizing enterocolitis: systematic review. Breastfeed Med. 2017; 12(9):528-36.

56. Kantorowska A, Wei JC, Cohen RS, Lawrence RA, Gould JB, Lee HC. Impact of donor milk availability on breast milk use and necrotizing enterocolitis rates. J Investig Med. 2016;137(3):e20153123.

\section{Publisher's Note}

Springer Nature remains neutral with regard to jurisdictional claims in published maps and institutional affiliations.

Ready to submit your research? Choose BMC and benefit from:

- fast, convenient online submission

- thorough peer review by experienced researchers in your field

- rapid publication on acceptance

- support for research data, including large and complex data types

- gold Open Access which fosters wider collaboration and increased citations

- maximum visibility for your research: over $100 \mathrm{M}$ website views per year

At $\mathrm{BMC}$, research is always in progress.

Learn more biomedcentral.com/submission 